Vol. 2 No. 2 (2019)

\title{
PARTAI POLITIK DAN INKONSISTENSI KOALISI DALAM PEMILU 2014 DAN 2019
}

\author{
Kunkunrat $^{1} \&$ Ade Priangani ${ }^{2}$ \\ ${ }^{1}$ Universitas Pasundan \\ kunkunrat@unpas.ac.id \\ ${ }^{2}$ Universitas Pasundan \\ ade.priangani@unpas.ac.id
}

Doi:

\begin{abstract}
Interesting events in the last 2 (two) elections, where there is a phenomenon of political parties contesting in the 2014 and 2019 elections trying to create an election that puts forward checks and balances between government support parties and opposition parties in the form of coalitions. In the 2014 elections there was a Great Indonesian Coalition (KIH) government, consisting of PDI-P, Nasdem, PKB, Hanura and PKPI, and the opposition Red and White coalition (KMP), consisting of Gerindra, Golkar, PAN, PKS, PPP and the United Nations. It is hoped that the people will have checks and balances so that the minority government is controlled by a large opposition. But that hope vanished as Golkar, PAN and PPP joined the government, so the opposition was no longer helpless, because it only left Gerindra and PKS. The recurring incident in the 2019 election, in which the presidential election gave birth to 2 coalition supporters of Jokowi-Maruf Amien Coalition of Working Indonesia (PDI-P, Nasdem, PKB, Hanura, PKPI, Golkar, PPP, Perindo, PSI) and the Coalition supporting Prabowo-Sandiaga, named The Indonesian Coalition is just and prosperous (Gerindra, PKS, PAN, Democrat), it is very apparent that there is a desire from PAN and Democrats to be part of the government coalition, inconsistencies occur in coalition in Indonesia.
\end{abstract}

Keywords: Political Parties, Coalition Inconsistencies, Elections.

\begin{abstract}
Abstrak
Kejadian menarik dalam 2 (dua) pemilu terakhir, dimana ada fenomena partai-partai politik yang berkontestasi dalam pemilu tahun 2014 dan 2019 berupaya untuk menciptakan sebuah pemilu yang mengedepankan check and balances antara partai pendukung pemerintah dan partai oposisi dalam bentuk koalisi. Dalam pemilu 2014 ada pemerintahan Koalisi Indonesia Hebat (KIH), terdiri dari PDI-P, Nasdem, PKB, Hanura dan PKPI, dan oposisi koalisi Merah Putih (KMP), terdiri dari Gerindra, Golkar, PAN, PKS, PPP dan PBB. Besar harapan rakyat terjadi check and balances sehingga pemerintah yang minoritas di kontrol oleh oposisi yang besar. Namun harapan itu sirna seiring dengan bergabungnya Golkar, PAN, dan PPP kedalam pemerintahan, sehingga oposisi tidak lagi berdaya, karena hanya meninggalkan Gerindra dan PKS. Kejadian berulang pada pemilu 2019, dimana dalam pilpres melahirkan 2 koalisi pendukung Jokowi-Maruf Amien Koalisi Indonesia Kerja (PDI-P, Nasdem, PKB, Hanura, PKPI, Golkar, PPP, Perindo, PSI) dan Koalisi pendukung
\end{abstract}


Prabowo-Sandiaga, yang bernama Koalisi Indonesia adil dan Makmur (Gerindra, PKS, PAN, Demokrat), sangat terlihat adanya keinginan dari PAN dan Demokrat untuk menjadi bagian dari koalisi pemerintah, terjadi inkonsistensi dalam berkoalisi di Indonesia.

\section{Kata kunci: Parpol, Inkonsistensi Koalisi, Pemilu.}

\section{Pendahuluan}

Pemilihan umum adalah proses substansial dalam penyegaran suatu pemerintahan. Andrew Reynolds menyatakan bahwa Pemilihan Umum adalah metode yang di dalamnya suarasuara yang diperoleh dalam pemilihan diterjemahkan menjadi kursi-kursi yang dimenangkan dalam parlemen oleh partai-partai dan para kandidat. Pemilihan umum merupakan sarana penting untuk memilih wakil-wakil rakyat yang benar-benar akan bekerja mewakili mereka dalam proses pembuatan kebijakan negara.

Pemilihan umum diikuti oleh partai-partai politik. Partai-partai politik mewakili kepentingan spesifik warganegara. Kepentingan-kepentingan seperti nilai-nilai agama, keadilan, kesejahteraan, nasionalisme, antikorupsi, dan sejenisnya kerap dibawakan partai politik tatkala mereka berkampanye. Sebab itu, sistem pemilihan umum yang baik adalah sistem yang mampu mengakomodasi kepentingan-kepentingan yang berbeda di tingkat masyarakat, agar terwakili dalam proses pembuatan kebijakan negara di parlemen.

Pemilu atau Pemilihan Umum yaitu proses memilih orang untuk dijadikan pengisi jabatan-jabatan politik tertentu, mulai dari presiden, wakil rakyat di berbagai tingkat pemerintahan sampai dengan kepala desa. Juga bisa dikatakan sebagai salah satu upaya dalam mempengaruhi rakyat secara persuasif (tidak memaksa) dengan melaksanakan aktivitas retorika, hubungan politik, komunikasi massa, lobi dan aktivitas lainnya. Pengertian pemilu menurut Undang-Undang Nomor 8 Tahun 2012 pasal 1 ayat adalah sarana pelaksanaan kedaulatan rakyat dalam Negara Kesatuan Republik Indonesia yang berdasarkan Pancasila dan Undang-Undang Dasar Negara Republik Indonesia tahun 1945. (Undang-Undang Nomor 8 Tahun 2012 pasal 1 ayat (1))

Tujuan dari pemilu adalah sebagai perwujudan kedaulatan rakyat untuk menghasilkan pemerintahan negara yang berdasarkan Pancasila dan UUD 1945. Sistem pemilihan umum berdasarkan pendapat Dieter Nohlen terdapat dua definisi. Yaitu pengertian sistem pemilu dalam arti luas dan dalam arti sempit.

Dalam arti luas, sistem pemilu adalah segala proses yang berkaitan dengan hak pilih, administrasi pemilihan dan perilaku pemilih. Sedangkan dalam arti sempit, sistem pemilihan umum yaitu cara dimana pemilih bisa mengekspresikan pilihan politiknya dengan cara memberikan suara, dimana suarat tersebut ditransformasikan menjadi kursi di parlemen atau pejabat publik.

Harapan terbangunnya sebuah sistem pemerintahan yang mengerucut menjadi dua kekuatan besar sempat mengemuka pasca Pilpres 2014, ketika partai-partai politik penyokong Prabowo Subianto-Hatta Radjasa (Gerindra, Golkar, PAN, PKS, PPP dan PBB) mendeklarasikan Koalisi Merah Putih (KMP), dan selanjutnya partai- 
partai pendukung Jokowi-Jusuf Kalla (PDI-P, Nasdem, PKB, Hanura dan PKPI) berhimpun dalam wadah Koalisi Indonesia Hebat (KIH). Deklarasi KMP pada saat itu diyakini oleh para pemerhati politik sebagai langkah awal untuk membangun koalisi permanen sampai pada tingkatan yang paling bawah. Keyakinan itu diperkuat oleh sikap KMP yang mendorong Pilkada tidak langsung, dengan tujuan untuk mendapatkan kekuasaan di daerah, sebab partai-partai politik yang bernaung dalam KMP memiliki keterwakilan yang lebih besar di hampir setiap daerah, sehingga peluang untuk mengambil jabatan kepala daerah sangat besar. KMP memiliki harapan besar untuk mendapatkan kekuasaan di lebih dari $80 \%$ daerah, sebab pada waktu pemilihan legislatif dimenangkan oleh partai-partai pendukung KMP.

Munculnya dua kekuatan dalam blantika politik Indonesia, ada harapan peta kekuatan politik akan mengerucut pada persaingan dua kekuatan besar, persaingan yang sehat seperti halnya di AS antara partai Republik dengan Demokrat, di Inggris Partai Buruh dengan Konservatif. Di dua negara tersebut, partai politik lebih dari 2, namun mereka berafiliasi dalam dua kekuatan politik diatas. Ketika yang satu berkuasa yang lainnya akan menjadi oposan sebagai alat kontrol bagi pemerintah. Harapan tersebut sirna seiring dengan dengan bergabungnya Golkar, PAN dan PPP kedalam koalisi pemerintah.

Setali tiga uang dalam pemilu 2019, dimana masyarakat terbelah pada dua koalisi, yaiti Koalisi Indonesia Kerja (PDI-P, Nasdem, PKB, Hanura, PKPI, Golkar, PPP, Perindo, PSI) dan Koalisi pendukung Prabowo-Sandiaga, yang bernama Koalisi Indonesia adil dan Makmur (Gerindra, PKS, PAN,
Demokrat), endingnya adalah adanya pergeseran kekuatan terutama yang sedang intens merapat ke pemerintahan yaitu Demokrat dan PAN.

Lalu dalam penyelenggaraan Pemilihan Kepala Daerah (Pilkada), koalisi malah lebih cair, artinya bisa saja koalisi yang dibangun untuk mengusung pasangan dari partai lintas koalisi besar, atau semua partai politik baik dari KIH maupun KMP mendukung satu pasangan yang memiliki kekuatan super dan diyakini akan memenangkan Pilkada. Bahkan yang membingungkan adalah adanya koalisi yang dilakukan oleh PDI-P dengan Gerindra, padahal kedua parpol tersebut adalah lokomotor di dua kubu yang berbeda dalam koalisi di tingkat nasional.

Partai-partai politik pada akhirnya memiliki sikap pragmatis yang menguntungkan bagi elite-elite lokal. Koalisi di daerah lebih berorientasi pada siapa yang berpeluang menjadi kepala daerah dibandingkan dengan platform partai, bahkan tidak jarang partai utama di KIH dan KMP bersama-sama mendukung satu pasangan.

Pertimbangan politik yang pragmatis dari partai-partai politik di Indonesia membuat masyarakat mengelus dada, dan bertanya masih adakah harapan untuk membangun kedewasaan politik ? atau masihkah ada pertimbangan idiologis dalam sikap partai politik?

\section{Pembahasan}

Koalisi adalah sebuah kelaziman dalam kontestasi politik di negara-negara yang berpaham demokrasi parlementer, tujuannya adalah untuk membangun kekuatan dari partai-partai politik yang notabene tidak dominan, apalagi dikaitkan dengan ketentuan-ketentuan dari penyelenggara pemilu yang tidak 
memungkinkan suatu partai politik sendirian berkontestasi dalam pemilu. Untuk memperbesar peluang menang, partai politik perlu mendapat mitra untuk memenuhi persyaratan dan sekaligus memperbesar peluang memenangkan kontestasi. Dalam pemerintahan dengan sistem parlementer, sebuah pemerintahan koalisi adalah sebuah pemerintahan yang tersusun dari koalisi beberapa partai sedangkan oposisi koalisi adalah sebuah oposisi yang tersusun dari koalisi beberapa partai.

Maka menjadi sebuah kemajuan dalam berdemokrasi di Indonesia, partai-partai politik berafiliasi dalam koalisi yang mempertimbangkan ideologi, platform partai dan kesamaan arah dalam membangun bangsa. Namun yang disayangkan adalah inkonsistensi partai politik dalam berkoalisi.

Koalisi idealnya bersandarkan pada kesamaan visi, misi atau juga orientasi untuk membangun kondisi Indonesia ke depan yang lebih baik, sehingga dengan demikian masingmasing koalisi akan menampilkan program-program yang terbaik untuk menarik simpati masyarakat, supaya dalam pemilu dan atau pilkada selanjutnya memilih partai-partai pendukung koalisi atau memilih Presiden dan Kepala Daerah yang didukung oleh koalisi tersebut.

Bangunan koalisi idealnya tidak dibangun diatas pasir agar tetap kokoh sampai ke bawah. Kekuatan koalisi selayaknya tidak hanya di permukaan atau dalam jajaran elite saja, namun sebaiknya juga melibatkan pelakupelaku politik di daerah. Kalau bangunan itu kokoh, maka tidak ada perbedaan antara koalisi di elite berbeda dengan koalisi di daerah, atau keluarnya partai pendukung dari koalisi seperti yang dilakukan oleh Partai Amanat
Nasional (PAN), yang berubah haluan masuk menjadi bagian pemerintah yang diusung oleh KIH.

Ketidakajegan koalisi tersebut karena elite lokal atau juga partai yang keluar dari koalisi hanya sekedar mengejar tujuan jangka pendek (kekuasaan). Hal ini tidak terlepas dari kurang kuatnya ikatan komitmen dari koalisi yang dibangun. Tidak ada jaminan dari koalisi untuk meyakinkan anggota koalisinya, bahwa langkah yang diambil adalah langkah yang terbaik, baik secara materil maupun non-materil.

Dalam kedudukannya sebagai pilar demokrasi, peran partai politik dalam sistem perpolitikan nasional merupakan wadah seleksi kepemimpinan nasional dan daerah. Pengalaman dalam rangkaian penyelenggaraan seleksi kepemimpinan nasional dan daerah melalui pemilu membuktikan keberhasilan partai politik sebagai pilar demokrasi.

Peran partai politik telah memberikan kontribusi yang signifikan bagi sistem perpolitikan nasional, terutama dalam kehidupan masyarakat Indonesia yang dinamis dan sedang berubah. Jika kapasitas dan kinerja partai politik dapat ditingkatkan, maka hal ini akan berpengaruh besar terhadap peningkatan kualitas demokrasi dan kinerja sistem politik. Oleh karena itu, peran partai politik perlu ditingkatkan kapasitas, kualitas, dan kinerjanya agar dapat mewujudkan aspirasi dan kehendak rakyat dan meningkatkan kualitas demokrasi.

Idiologi partai atau katakanlah platform partai, seyogyanya menjadi orientasi bagi semua anggotanya. Artinya kalau platform sudah ditetapkan sebagai orientasi partai maka semua komponen dalam partai tersebut menyesuaikan dengan keinginan 
bersama yang telah ditetapkan menjadi platform partai.

Sikap pragmatisme partai politik dalam pilkada memang tidak salah, namun hal ini menunjukkan kedangkalan tafsiran tentang politik, yang hanya diterjemahkan untuk meraih kekuasaan dengan berbagai cara.

Ketidakselarasan antara keinginan pimpinan pusat partai dengan pimpinan politik di daerah menyebabkan konstalasi koalisi di Pilkada tahun 2015 ini sangat beranekawarna, pertautan relasi antar partai politik tidak tetap. Selayaknya apabila PDI-P, Nasdem, PKB, Hanura dan PKPI sudah menetapkan berorientasi pada koalisi Indonesia Hebat atau Gerindra, Golkar, PAN, PKS, PPP dan PBB sudah menetapkan orientasi partai dengan memakai kendaraan KMP, maka seluruh komponen dibawahnya menyelaraskan dengan platform yang sudah ditetapkan oleh partai.

Namun koalisi dalam Pilkada ini sangat kompleks, sebab pola hubungan koalisi tidak sama antara satu daerah dengan daerah yang lainnya. Menurut data KOMPAS, $77,7 \%$ parpol dalam pilkada cenderung membangun koalisi campuran, tidak memandang koalisi di tingkat nasional.

Melihat fenomena tersebut, maka perlu kiranya setiap partai politik mengoptimalkan pendidikan politik untuk membangun karakteristik politik partai. Dalam pendidikan politik juga harus ditekankan pentingnya etika politik sebagai fondasi membangun dan mengembangkan partai. Benang kusut koalisi parpol dalam pilkada menunjukkan bahwa partai politik kurang mampu untuk mengendalikan pengurus di daerah, sekaligus sebagai bukti kegagalan dalam pendidikan politik bagi anggotanya.

\section{Koalisi Dalam Pemilu 2014}

Pemilihan presiden dan wakil presiden tahun 2014 diikuti oleh 2 pasangan calon presiden dan wakil presiden, yaitu Prabowo Subianto-Hatta Rajasa, dan Joko Widodo-Jusuf Kalla. Joko Widodo dan Jusuf Kalla memperoleh suara 53,15\% ditetapkan oleh KPU RI pada 22 Juli 2014 dan dengan demikian terpilih menjadi Presiden-wakil presiden menggantikan Susilo Bambang Yudhoyono-Budiono.

Dalam pencalonannya Joko Widodo dan Jusuf Kalla didukung oleh Partai Demokrasi Indonesia Perjuangan (PDIP), Partai Kebangkitan Bangsa (PKB), Partai Nasdem, Partai Hati Nurani Rakyat (Hanura) dan Partai Keadilan dan Perstuan Indonesia (PKPI), tergabung dalam Koalisi Indonesia Hebat.

Pasca Pilpres 2014, partai-partai politik mengerucut menjadi dua kelompok besar di parlemen (DPR RI), yaitu partai-partai politik penyokong Prabowo Subianto-Hatta Radjasa (Gerindra, Golkar, PAN, PKS, PPP dan PBB) mendeklarasikan Koalisi Merah Putih (KMP) menjadi oposan terhadap pemerintahan terpilih Joko WidodoJusuf Kalla, dan partai-partai pendukung Jokowi-Jusuf Kalla (PDI-P, Nasdem, PKB, Hanura dan PKPI) berhimpun dalam wadah Koalisi Indonesia Hebat (KIH) sebagai koalisi pendukung pemerintah.

Sehubungan dengan terpilihnya Jokowi-JK sebagai Presiden dan Wakil Presiden Republik Indonesia periode 2014-2019, maka Koalisi Indonesia Hebat menjadi koalisi partai politik pendukung pemerintah.

Pasca kemenangan Jokowi-JK, Koalisi pendukung pemerintah bertambah, seiring dengan membelotnya Golkar, PAN, dan PPP kedalam koalisi pendukung pemerintah, 
sehingga ketika penyusunan kabinet ada power sharing dengan ketiga partai yang tadinya pendukung PrabowoHatta, sehingga komposisi menteri 5 menteri dari PDI-P, 2 menteri dari Partai Golkar, 2 menteri dari Partai NasDem, 4 menteri dari PKB, 1 menteri dari PAN, 1 menteri dari Partai Hanura, dan 1 menteri dari PPP.

Namun berkaitan dengan Pilkada, koalisi di tingkat pusat ternyata tidak selaras dengan koalisi dalam Pilkada. Kerap kali terjadi, diantara dua kutub besar Indonesia Hebat dan Merah Putih, berseberangan dengan anggota koalisi dan bermitra dengan lawan koalisi, seperti misalnya di Jawa Barat, PDIP sendirian mendukung pasangan TB. Hasanudin-Anton Charliyan, sementara PPP, PKB, Nasdem, dan Hanura mendukung Ridwan Kamil-Uu Ruzhanul Ulum. Golkar memilih bergabung dengan Demokrat menjagokan Deddy Mizwar-Dedi Mulyadi, dan koalisi Merah Putih yang tersisa Gerindra dan PKS, menggandeng PAN untuk mendukung Sudrajat-Achmad Syaikhu. Jadi koalisi di tingkat nasional KIH (PDIP, PPP, PKB, Nasdem, Hanura, Golkar, dan PAN) memilih berpencar, dan ada diantaranya yang bergabung dengan Koalisi Merah Putih, yaitu PAN bergabung dengan Gerindra dan PKS, serta Golkar memilih gabung dengan Demokrat yang netral, dan PDIP memisahkan diri sendirian.

Untuk Sumatera Utara, Koalisi Indonesia Hebat, terpecah dua, ada yang bergabung dengan lawan koalisi (Gerindra dan PKS) serta Demokrat untuk mendukung Edy RahmayadiMusa Rajekshah, yaitu Golkar, Hanura, Nasdem, PAN, Perindo, dan PKB. Sedangkan PDIP, PPP, PKPI dan PSI lebih memilih untuk mendukung pasangan Djarot Syaiful Hidayat-Sihar Sitorus.

Di Jawa Tengah, anggota Koalisi Indonesia Hebat, yaitu PDIP, PPP dan Nasdem, bergandengan dengan Demokrat untuk mendukung Ganjar Pranowo-Taj Yasin Maimoen. Sedangkan PKB dan PAN memilih berpasangan dengan koalisi Merah Putih yang tersisa yaitu Gerindra dan PKS, untuk mendukung Sudirman SaidIda Fauziah.

Sedangkan untuk Jawa Timur, anggota Koalisi Indonesia Hebat yaitu Golkar, PPP, Nasdem, PAN, Hanura, PKPI, PSI memilih bersama Demokrat untuk mendukung Khofifah Indar Parawansa-Emil Dardak, daripada bersama PDIP. Sedangkan yang paling menarik untuk Jawa Timur adalah pendukung utama Koalisi Indonesia Hebat, yaitu PDIP bersama PKB dan Perindo, berada dalam satu kubu dengan Gerindra dan PKS mendukung Saifulah Yusuf-Puti Guntur Soekarno.

Di Sulawesi Selatan, yang paling menarik adalah pecahnya dukungan Gerindra dengan PKS. Gerindra memilih bareng dengan PPP dan PBB mendukung Agus Arifin Nu'mangTanribali Lamo, sedangkan PKS memilih bareng PDIP dan PAN untuk mendukung Nurdin Abdulah-Sudirman Sulaiman. Sementara Golkar, Nasdem, Hanura, PKB dan PKPI mendukung Nurdin Halid- Aziz Qahhar Mudzakkar.

Dilihat dari contoh-contoh Pilkada diatas, jelaslah bahwa koalisi di Indonesia masih cair dan tidak idiologis. Apalagi kalau kita tampilkan data-data Pilkada di tingkat Kabupaten dan Kota, bisa jadi lebih beragam.

\section{Nasib Koalisi Pasca Pemilu 2019}

Untuk Pemilu tahun 2019 pun Koalisi yang terjadi bisa jadi sama dengan koalisi pasca pemilu 2014. Meskipun 
penamaan koalisi berbeda, namun gaya dan tingkah lakunya sama. Dalam Pilpres 2019 pun, koalisi yang hadir adalah 2 (dua), sesuai dengan jumlah kandidat presiden. Joko Widodo-Ma'ruf Amien didukung oleh Koalisi Indonesia Kerja (PDIP, PKB, PPP, Golkar, Hanura, Nasdem, Perindo, PSI), sedangkan pasangan Prabowo SubiantoSandiaga Uno didukung oleh Koalisi Indonesia Adil Makmur (Gerindra, PKS, PAN dan Demokrat).

Pemilu 2019, dirasakan sebagai pemilu yang paling panas, yang dihadapi oleh bangsa Indonesia, berbagai politiking dan hoaks menjadi warna dominan, ditambah bumbubumbu seperti politik Indentitas, tuduhan kecurangan, darah yang tercecer, ratusan penyelenggara pemilu yang meninggal, teriakan kemenangan, dan juga teriakan kekecewaan.

Namun pasca pemilu 2019, di prediksi sama dengan yang terjadi pasca pemilu 2014. Ketika itu ada tiga partai, yang semula menjadi bagian dari koalisi pendukung Prabowo-Hatta, kemudian berpindah haluan bergabung dalam koalisi pendukung presiden terpilih, yaitu Golkar, PPP dan PAN, dan kemudian Golkar dan PPP menjadi pendukung Joko Widodo dalam Pilpres 2019, sedang PAN memilih kembali ke koalisi pendukung Prabowo.

Pada pasca Pilpres 2019 pun, besar kemungkinan dilihat dari manuver para petinggi partai, PAN akan kembali memberikan dukungan kepada koalisi pendukung presiden terpilih bersamasama dengan partai Demokrat. Dan akan lebih menarik lagi apabila Gerindra pun turut dalam koalisi pendukung pemerintah.

\section{Refleksi Pemilu}

Terlepas dari dinamika politik Indonesia yang riuh semasa Pilpres dan kemudian tenang kembali pasca pemilu, ternyata ada berbagai masalah yang tersisa pasca pemilu, yaitu:

Pertama, ternyata pemilu di Indonesia ini tidak murah. Kementerian Keuangan (Kemenkeu) mengeluarkan anggaran sebesar Rp 25,59 triliun untuk kegiatan pemilihan umum (Pemilu) serentak pada 17 April 2019.(Detikfinance, 27 Maret 2019). Alokasi anggaran untuk persiapan awal di tahun 2017 sekitar Rp 465,71 miliar; kemudian pada 2018 (alokasi) mencapai Rp 9,33 triliun, dan di tahun $2019 \mathrm{Rp}$ 15,79 triliun, jadi total dalam 3 tahun Rp 25,59 triliun.

Kedua, penyatuan penyelenggaraan Pileg dan Pilpres menyebabkan beban kerja penyelenggara pemilu menjadi berat. Hal itu bisa terlihat dari begitu banyaknya korban meninggal dan sakit penyelenggara pemilu. Cost yang harus ditanggung oleh bangsa Indonesia adalah kehilangan 554 orang penyelenggara pemilu (baik dari pihak Komisi Pemilihan Umum (KPU), Badan Pengawas Pemilu (Bawaslu) maupun personel Polri). (CNNIndonesia, 7 Mei 2019). Selain yang meninggal, sebanyak 398 orang rawat inap di rumah sakit, 1.592 rawat jalan, 250 orang mengalami kecelakaan, 14 orang cacat tetap, dan 14 petugas mengalami keguguran.

Ketiga, Netralitas penyelenggara Pemilu, ada tudingan bahwa penyelenggara Pemilu menguntungkan bagi Petahana. Titik permasalahannya adalah, bahwa personal KPU dari Pusat sampai kebawah dipilih dan dibiayai oleh pemerintah, dan begitu pula anggaran untuk penyelenggaraan pemilu juga di keluarkan oleh pemerintah, yang notabene adalah menjadi kandidat kembali sebagai calon petahana. 
Keempat, adanya kandidat petahana, kerap kali dan mungkin selalu, Petahana menuai tudingan telah memanfaatkan pemerintahannya untuk kepentingan melanggengkan kekuasaan. Sejujur apapun petahana, akan tetap menuai dugaan yang jelek. Sehingga ada asumsi, jika seorang kandidat melawan petahana, kekuatannya harus $200 \%$, kecuali ada masalah dengan petahana, seperti kasus di Ukraina. Kemenangan Volodymyr Zelenskiy, atas calon petahana, Poroshenko yang mencapai 73,4 persen suara dikarenakan masyarakat sudah muak dengan calon petahana.

Kelima, terlalu besarnya "Presidential Threshold" yang 20\%, sehingga menutup peluang kandidat yang potensial diluar dari kandidat dukungan parpol. Hal ini yang menyebabkan hanya dua kandidat yang terpilih, sehingga suasananya saling berhadapan, sehingga membelah masyarakat kedalam dua kubu. Kalau seseorang tidak dalam kubu 01, maka dianggap sebagai bagian dari 02, begitu pula sebaliknya, padahal ketika seseorang tidak di salah satu kubu, belum tentu berada di kubu sebelah.

Dari berbagai masalah tersebut, tentu saja ini membuka peluang seluruh elemen masyarakat untuk urun rembug memikirkan solusi terbaik bagi kehidupan politik Indonesia di masa depan. Kita tidak mau, bangsa ini terbelah karena perbedaan dukungan dalam Pilpres. Terlalu murah pecahnya suatu negara gara-gara perbedaan pilihan dalam Pilpres.

Maka karena ini, dalam benak penulis ada beberapa hal yang bisa dijadikan sebagai salah satu alternatif dalam menunjukkan eksistensi demokrasi di Indonesia.

Pertama, Pemilu diselenggarakan 8 atau 10 tahun sekali. Hal ini dilandasi oleh kenyataan bahwa ketika masa kerja Presiden 5 tahun, maka kinerja tidak maksimal, karena sudah menjadi kelaziman, tahun pertama kekuasaan dijadikan sebagai sarana mapping masalah, tahun kedua pematangan program kerja, tahun ketiga dan keempat kerja, tahun kelima, persiapan untuk mempertahankan kekuasaan dengan pemilu lagi. Jika pemerintahan 8 tahun umpamanya, maka akan terdapat 6 tahun untuk kerja, dibanding dengan 2 periode 5 tahunan yang efektifnya kerja cuma 4 (empat) atau 5 (lima) tahun. Apalagi kalau periodenya 10 tahun, terdapat 8 (delapan) tahun untuk bekerja, tanpa diiringi rasa was-was dalam mengelola negara. Namun kesempatan untuk menjadi presiden dibatasi 1 (satu) periode.

Disamping efektifitas kinerja, juga terjadi penghematan besar bagi negara, karena akan menghemat 1 (satu) periode anggaran. Umpamanya kalau 5 tahunan, maka akan dikeluarkan $2 \mathrm{Rp}$ 25,59 triliun, atau sekitar 51,18 triliun selama sepuluh tahun, sedangkan kalau diselenggarakan 10 tahun sekali hanya dibutuhkan Rp 25,59 triliun, jadi menghemat $\mathrm{Rp} 25,59$ triliun.

Model ini juga menghilangkan adanya persaingan antara petahana dengan penantang. Karena kekuasaan dibatasi satu periode dengan durasi antara 8 atau 10 tahun, maka setiap pemilu akan melahirkan persaingan sama-sama pendatang baru, sehingga masyarakat lebih objektif dalam memilih pemimpinnya. Dugaan selama ini yang menganggap petahana akan selalu diuntungkan menjadi tidak berlaku lagi, karena presiden sebelumnya tidak bisa lagi mencalonkan diri menjadi kandidat presiden berikutnya.

Kedua, pemisahan antara pileg (pemilihan legislatif) dengan pilek 
(pemilihan eksekutif). Berkaca dari pengalaman pemilu 2019, dimana ada penyatuan antara pileg dan pilpres, menyebabkan bobot pileg tidak terlalu menarik, karena daya tarik tertumpah pada pilpres, banyak masyarakat yang tidak peduli dengan pileg, bahkan secara umum mereka yang terpilih menjadi anggota legislatif mayoritas nomor 1 di partainya, karena masyarakat tidak sempat menimbangnimbang siapa diantara kandidat dari suatu partai yang terbaik visi misinya dan sebagainya, karena konsentrasi sudah tersita oleh pilpres dan memilih pileg juga disesuaikan dengan partai pendukung presiden, dan rata-rata tidak memilih nomor, hanya partai saja. Sehingga kualitas anggota legislatif banyak dipertanyakan oleh masyarakat.

Disamping output pileg yang bermasalah dengan model ini adalah beban kerja pelaksana pemilu, baik yang berada dalam lingkup KPU, Bawaslu ataupun Kepolisian yang mengalami kelelahan. Jumlah korban yang meninggal diatas 500 orang adalah sebuah musibah. Maka langkah yang efektif adalah memisahkan kembali antara pileg dan pilpres, namun yang menjadi catatan perlunya dipertimbangkan untuk menyatukan antara pilpres dengan pilkada.

Ketiga, percepatan publikasi hasil pemilu dengan cara menghitung langsung formulir C-1. Perlu dipersiapkan perangkat yang dapat membaca secara langsung formulir C-1 terintegrasi dengan data base KPU pusat (seperti hitung cepat selama ini yang dilakukan oleh lembaga survey), tanpa melalui jenjang penghitungan dari level Kelurahan, Kecamatan, Kabupaten dan Provinsi. Selain kecepatan publik untuk mengetahui hasil pemilu, juga mengeleminir tudingan dan tuduhan serta peluang terjadinya kecurangan, yang selama ini diperdebatkan.

Keempat, penyelenggara pemilu dari kalangan kampus, yang tidak berafiliasi pada salah satu kekuatan politik, seperti yang dilaksanakan pada pemilu 2004. Hal ini untuk menghindari konflik kepentingan diantara penyelenggara pemilu, yang harus membalas budi kepada orang yang memilihnya.

Demikianlah harapan-harapan yang berkembang di masyarakat, yang menginginkan hasil pemilu diterima oleh semua kalangan dengan senyuman, bukan tuduhan dan cacimaki, bahkan konflik yang berkepanjangan di tengah masyarakat.

Pemilu selayaknya ditempatkan pada koridornya sebagai alat untuk melakukan rulling class di sebuah negara, untuk menghindari terjadinya pergantian pemerintahan dengan cara kekerasan seperti coup d'etat dan sejenisnya yang akan merugikan rakyat dari barbagai sudut dan kepentingan.

Pemilu diharapkan tidak melahirkan sesuatu yang horor, namun sebuah pesta bagi rakyat untuk menyuarakan keinginan dan harapannya dengan rasa optimisme, dan selesai pesta semua puas, semua senyum.

\section{DAFTAR PUSTAKA}

Andrew Reynolds, et.al., Electoral System Design: The New International IDEA Handbook, (Stockholm: International Institute for Democracy and Electoral Assistance, 2005).

Dieter Nohlen, "Electoral Systems" dalam Lynda Lee Kaid and Christina Holtz-Bacha, Encyclopedia of political communication, (California: Sage Publications, 2008) 
Hanta Yuda AR, Presidensialisme Setengah Hati, (Jakarta: Gramedia Pustaka Utama, 2010).

Jimly Asshiddiqie, Pengantar Ilmu Hukum Tata Negara, (Jakarta, Rajawali Pers: 2008).

Matias Iaryczower and Andrea Mattozzi, "Ideology and Competence in Alternative Electoral Systems", Paper, Division of Humanities and Social Sciences, California Institute of Technology, Pasadena, California, July 9, 2008.
Maurice Duverger, 1967. Political Parties. ISBN-13: 9780471228653. Publisher: Wiley.

Miriam Budiarjo,Dasar-Dasar Ilmu Politik, (Jakarta, Gramedia Pustaka Utama: 2015).

Undang-Undang UU Nomor 12 Tahun 2003 tentang Pemilu Anggota DPR, DPD dan DPRD.

UU Nomor 17 Tahun 2017 tentang Pemilihan Umum.

Detikfinance, 27 Maret 2019

CNNIndonesia, 7 Mei 2019 